\title{
Retraction Note to: Feature extraction and ML techniques for static gesture recognition
}

\author{
Haitham Badi $^{1} \cdot$ Sabah Hasan Hussein ${ }^{2}$ Sameem Abdul Kareem ${ }^{1}$
}

Published online: 15 February 2017

(C) The Natural Computing Applications Forum 2017

\section{Retraction Note to: Neural Comput \& Applic \\ (2014) 25:733-741 \\ DOI 10.1007/s00521-013- 1540-6}

The Editor-in-Chief and the Publisher retract the abovementioned article due to self-plagiarism. The article has significant overlap with two other publications by the same co-author:

- Haitham Sabah Hasan, Sameem Binti Abdul Kareem, Gesture Feature Extraction for Static Gesture Recognition, Arabian J. for Science and Engineering (2013) 38:12. doi:10.1007/s13369-013-0654-6

- Haitham Hasan, S. Abdul-Kareem, Static Hand Gesture Recognition Using Neural Networks, Artificial Intelligence Review (2014) 41:2. doi:10.1007/s10462-0119303-1

The online version of the original article can be found under doi:10.1007/s00521-013-1540-6.

Haitham Badi

haitham875@yahoo.com

1 Faculty of Computer Science and Information of Technology,

University of Malaya, 50603 Kuala Lumpur, Malaysia

2 Al Yarmouk University College, Baghdad, Iraq 